\title{
Update on prescription extended-release opioids and appropriate patient selection
}

\author{
This article was published in the following Dove Press journal: \\ Journal of Multidisciplinary Healthcare \\ 22 July 2013 \\ Number of times this article has been viewed
}

\section{Michael J Brennan}

The Pain Center of Fairfield, Fairfield, CT, USA
Correspondence: Michael J Brennan

The Pain Center of Fairfield,

140 Sherman Street, 2A, Fairfield,

CT 06824, USA

Tel + I 203255345 I

Fax +I 2032557478

Email mjbmd58@aol.com

\begin{abstract}
Chronic pain is largely underdiagnosed, often undertreated, and expected to increase as the American population ages. Many patients with chronic pain require long-term treatment with analgesic medications, and pain management may involve use of prescription opioids for patients whose pain is inadequately controlled through other therapies. Yet because of the potential for abuse and addiction, many clinicians hesitate to treat their patients with pain with potentially beneficial agents. Finding the right opioid for the right patient is the first - often complicated - step. Ensuring that patients continue to properly use the medication while achieving therapeutic analgesic effects is the long-term goal. Combined with careful patient selection and ongoing monitoring, new formulations using extended-release technologies incorporating tamper-resistant features may help combat the growing risk of abuse or misuse, which will hopefully reduce individual suffering and the societal burden of chronic pain. The objective of this manuscript is to provide an update on extended-release opioids and to provide clinicians with a greater understanding of which patients might benefit from these new opioid formulations and how to integrate the recommended monitoring for abuse potential into clinical practice.
\end{abstract}

Keywords: chronic pain, opioid analgesics, extended release, abuse prevention

\section{Introduction}

Chronic pain is a societal problem that is likely to become increasingly significant with the aging of the American population. The most recent estimate from the Institute of Medicine suggests that at least 100 million American adults have chronic pain: more than those affected by heart disease, cancer, and diabetes combined. ${ }^{1}$ It is believed that $25 \%$ of American adults are affected by moderate to severe chronic pain, and $6 \%-13 \%$ of adults report severe disabling pain., ${ }^{2,3}$ The prevalence of chronic pain appears to be higher among women than men, ${ }^{2,3}$ and seems to increase with age. ${ }^{2-4}$ Chronic pain interferes with quality of life (QoL) and sleep; it leads to diminished cognitive function, impaired relationships, decreased productivity, and increased mental health concerns, particularly anxiety and depression. ${ }^{5-7}$

Despite its high prevalence, chronic pain remains underdiagnosed and undertreated. More than half of patients with pain are managed by their primary care physician; only $2 \%$ are managed by a pain specialist. ${ }^{3,8}$ Paradoxically, while nearly half of all patients with chronic pain receive inadequate analgesia, ${ }^{3,7,9,10}$ the use of prescription opioids for pain management has escalated to approximately $20 \%$ of all prescriptions. ${ }^{11}$ These findings suggest that some patients are receiving a disproportionately large amount of analgesics while others remain undertreated. 
Most patients with chronic pain receive long-term treatment with analgesic medications. Opioids are suggested when other, less problematic approaches are ineffective or poorly tolerated, or if the benefit-risk of their use is surpassed by opioids. ${ }^{12-14}$ However, there are issues associated with longterm opioid therapy for chronic noncancer pain, particularly with respect to the risk of tolerance, dependence, or abuse. ${ }^{15-18}$ While it is broadly accepted that chronic opioid therapy is associated with the development of tolerance, the exact nature of this and the extent to which it may limit the clinical utility of opioid therapy are still poorly characterized. ${ }^{19}$ Evidence of long-term improvements in functional activity is also inconclusive, and the continuing effectiveness of opioids taken chronically is difficult to quantify, as the quality of long-term efficacy studies varies widely. ${ }^{16}$ However, despite these concerns, multiple expert panels have concluded that chronic opioid therapy can be effective for patients with chronic noncancer pain who are carefully selected and monitored. ${ }^{17}$

The introduction of new extended-release (ER) formulations has provided physicians with a range of management options. More recently, a selection of putative abuse-deterrent formulations (ADFs) of these agents have also been employed. Early data suggest that these formulations may be impacting abuse specific to individual drugs, although no impact on community rates of abuse has so far been reported..$^{20}$ The objective of this review is to provide an update on ER opioids and to furnish clinicians with a greater understanding of which patients might benefit from these new opioid formulations and how recommended monitoring for abuse potential may be integrated into clinical practice.

\section{Managing chronic pain with extended-release opioids}

Several well-described reasons have been identified for limiting prescription of opioids for patients who might benefit from them. Clinicians are especially reluctant to prescribe opioid analgesics because of regulatory oversight concerns, documentation requirements, fear of abuse potential, and lack of foundational knowledge regarding these agents. ${ }^{8,21}$ Consequently, nearly one in three clinicians do not initiate opioid therapy. ${ }^{22}$ Recent data suggest this fear or lack of understanding exists across various diseases and clinical environments. For example, a recent study showed that onethird of patients with invasive cancer pain had inadequate analgesic prescribing, and minorities were twice as likely not to receive adequate pain medication. ${ }^{23}$ Furthermore, some patients may choose to live with some degree of chronic pain for various reasons (eg, to avoid common side effects of opioids or other analgesics). ${ }^{24}$ Patient-centered care must therefore encourage greater understanding of the appropriate use of opioids, to enable more patients with chronic pain to receive analgesia that is adequate for their requirements and to experience improvements in work capacity, functioning, and QoL, while minimizing abuse potential.

\section{Pharmacokinetics of extended-release formulations}

Prescription opioids can be categorized according to several different parameters, including affinity and selectivity for opioid receptors, pharmacodynamic effects, and pharmacokinetic profiles. Most commercially available prescription opioids exert clinical effects via interactions with mu-opioid receptors and produce a constellation of typical opioidmediated effects, including analgesia, sedation, nausea, constipation, and (potential) elevations in mood. Regarding their relative ability to produce such effects, opioid analgesics are categorized as either weak (eg, codeine, hydrocodone plus acetaminophen, and tramadol) or strong (eg, oxycodone, hydromorphone, morphine, fentanyl, and oxymorphone). ${ }^{25}$ Prescription opioids are available as immediate-release (IR) or ER formulations, distinguishing features that have relevance for their clinical utility. As with IR opioids, which typically have clinical effect for 3-6 hours, common side effects with ER formulations include constipation, nausea, and somnolence. ${ }^{26-31}$ In addition, respiratory depression and risk of death from overdose have been directly associated with higher opioid doses..$^{32}$

Compared with IR formulations, ER formulations are specifically designed to allow a controlled release of the active agent to provide relatively consistent and prolonged plasma drug levels with lower maximum concentration $\left(\mathrm{C}_{\max }\right)$ and fewer peak-to-trough fluctuations (Figure 1). ${ }^{26,33}$ To prevent gaps in pain relief, IR formulations require regular administration every 4-6 hours, and consequently produce numerous peaks and troughs in plasma drug levels throughout the day. In contrast, ER formulations are dosed less frequently (one to three times per day or fewer), allowing for less fluctuation and affording an elongated duration within the therapeutic window. ${ }^{34}$ In addition, a lower maximum daily dose has been associated with a reduced risk of respiratory depression and overdose. ${ }^{32}$ The time to peak blood concentration level $\left(T_{\max }\right)$ is generally longer with ER formulations, a parameter that may confer a reduced abuse liability when intact tablets are taken whole (see below). ${ }^{35,36}$ Two separate surveys, one sent to patients and the other to physicians, concluded that 


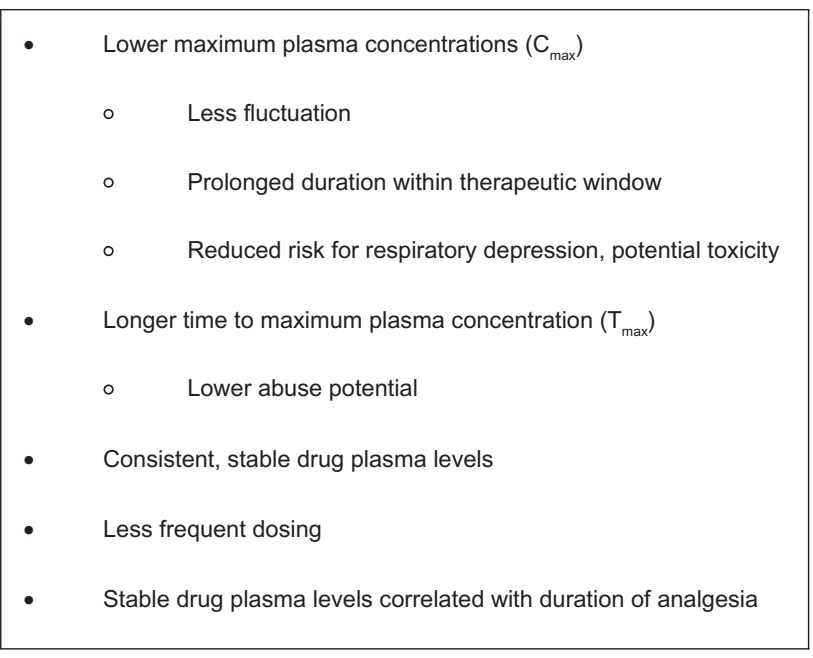

Figure I Putative pharmacokinetic advantages of extended-release versus immediate-release opioids. ${ }^{26,33}$

the two most important factors when selecting an opioid are the ability to relieve pain and the duration of pain relief. ${ }^{37}$ Studies demonstrate that duration of stable blood plasma levels is significantly correlated with the overall duration of analgesia. ${ }^{26,34}$

ER opioids have been shown to be efficacious for treatment durations of up to 1 year in patients with chronic nonmalignant pain associated with a variety of underlying etiologies, including low-back pain, ${ }^{38-44}$ osteoarthritis, ${ }^{40,41,45-47}$ postherpetic neuralgia, ${ }^{48}$ and neuropathic pain. ${ }^{49,50}$ Although prescriptions using IR preparations are far more prevalent than those using ER formulations,${ }^{51}$ few studies have directly compared ER with IR opioid formulations. At the time of this writing, there is no clear evidence to recommend one over the other. ${ }^{30,51,52}$ Additional head-to-head studies are necessary to elucidate the range of conditions under which ER opioids perform better.

\section{Extended-release opioid formulations}

A number of oral and transdermal ER opioid formulations are currently available (Table 1). ${ }^{53-66}$ Clinically important differences focus on the pharmacokinetics of individual agents and the benefits related to specific formulations. Potency, defined as the dose required to produce a given effect, is typically compared relative to morphine and differs not only between agents but also by both route of administration and whether the formulation is IR or ER.$^{67}$ Recent additions to the pharmacologic armamentarium include formulations designed to reduce abuse liability among the subset of people who manipulate existing formulations to obtain a faster or greater opioid response; although these ADFs cannot reduce or eliminate all means for opioid abuse, they may help deter particular forms of opioid abuse among specific populations.

\section{Morphine}

Morphine is considered the prototype of pure mu-agonist opioids. ${ }^{27}$ Oral controlled-, extended-, and sustained-release morphine formulations are available in the United States as tablets or capsules. Recent additions include a once-daily capsule formulation containing both IR and ER beads that release morphine in a distinct time-dependent manner using a spheroidal oral drug-absorption system, or SODAS (Avinza; King Pharmaceuticals, Bristol, TN, USA), and a once- or twice-

Table I Extended-release opioids ${ }^{53-66}$

\begin{tabular}{|c|c|c|c|c|}
\hline Opioid & Generic name & Brand name & Available doses & Dosing interval \\
\hline \multirow[t]{6}{*}{ Morphine } & Morphine sulfate ER capsules & Avinza & $30,45^{\mathrm{b}}, 60^{\mathrm{b}}, 75^{\mathrm{b}}, 90^{\mathrm{b}}, 120^{\mathrm{b}} \mathrm{mg}$ & Once daily \\
\hline & Morphine sulfate and naltrexone & Embeda $^{a}$ & $-{ }^{\mathrm{a}}$ & Once or twice daily \\
\hline & $\mathrm{HCl}$ ER capsules & & & \\
\hline & Morphine sulfate ER capsules & Kadian & $\begin{array}{l}10,20,30,40,50,60,70,80 \\
100^{b}, 130,150,200^{\mathrm{b}} \mathrm{mg}\end{array}$ & Once or twice daily \\
\hline & Morphine sulfate CR tablets & MS Contin & $15,30,60,100^{\mathrm{b}}, 200^{\mathrm{b}} \mathrm{mg}$ & Every $8-12$ hours \\
\hline & Morphine sulfate SR tablets & Oramorph SR & $15,30,60,100 \mathrm{mg}$ & Every 8-12 hours \\
\hline Oxymorphone & Oxymorphone $\mathrm{HCl}$ ER tablets & Opana ER & $5,10,20,30,40 \mathrm{mg}$ & Every 12 hours \\
\hline Hydromorphone & Hydromorphone $\mathrm{HCl}$ ER tablets & Exalgo & $8^{\mathrm{b}}, 12^{\mathrm{b}}, 16^{\mathrm{b}}, 32^{\mathrm{b}} \mathrm{mg}$ & Once daily \\
\hline Tapentadol & Tapentadol ER oral tablets & Nucynta ER & $50,100,150,200,250 \mathrm{mg}$ & Every 12 hours \\
\hline Oxycodone & Oxycodone $\mathrm{HCl} \mathrm{CR}$ tablets & OxyContin & $10,15,20,30,40,60^{\mathrm{b}}, 80^{\mathrm{b}} \mathrm{mg}$ & Every 12 hours \\
\hline \multirow[t]{2}{*}{ Methadone $^{c}$} & Methadone $\mathrm{HCl}$ tablets & Dolophine & $5,10 \mathrm{mg}$ & Every $8-12$ hours \\
\hline & & Methadose & $10 \mathrm{mg}$ & \\
\hline Fentanyl & Fentanyl transdermal system & Duragesic & $12^{\mathrm{b}}, 25^{\mathrm{b}}, 50^{\mathrm{b}}, 75^{\mathrm{b}}, 100^{\mathrm{b}} \mathrm{mcg} / \mathrm{hour}$ & I patch every 72 hours \\
\hline Buprenorphine ${ }^{d}$ & Buprenorphine transdermal system & Butrans & $5,10,20 \mathrm{mcg} / \mathrm{hour}$ & I patch weekly \\
\hline
\end{tabular}

Notes: ${ }^{\mathrm{E} E m b e d a}$ is not currently being marketed in the United States; ${ }^{b}$ doses available only for opioid-tolerant patients; ${ }^{\mathrm{c}} \mathrm{methadone}$ is the only medication considered a long-acting opioid formulation; 'Schedule III agent.

Abbreviations: $\mathrm{CR}$, controlled release; $\mathrm{ER}$, extended release; $\mathrm{HCl}$, hydrochloride; $\mathrm{SR}$, sustained release. 
daily ER capsule (Kadian; Actavis Elizabeth, Morristown, NJ, USA). ${ }^{27,54,56,68}$ The once-daily formulation provides the same total systemic exposure over 24 hours as the twice-daily formulation, but with different pharmacokinetics, including a lower $\mathrm{C}_{\max }$ and higher $\mathrm{C}_{\min }$, resulting in reduced peak-to-trough fluctuations compared with the twice-daily formulation. ${ }^{27,68,69}$ The controlled-release (MS Contin; Purdue Pharma, Stamford, CT, USA) and sustained-release formulations (Oramorph SR; Xanodyne Pharmaceuticals, Newport, KY, USA) are dosed every 12 hours but can be dosed every 8 hours for patients whose pain is not fully controlled over the 12-hour release time. ${ }^{57,58}$ An ADF that combines morphine sulfate with naltrexone hydrochloride has been developed, but is not currently being marketed (Embeda; King Pharmaceuticals). ${ }^{55}$ For all available morphine formulations, studies suggest that food impacts the pharmacokinetics, predominantly by increasing $\mathrm{T}_{\max }$, although some research suggests that food can also increase the area under the curve (AUC) and $\mathrm{C}_{\max }$ for IR and specific ER morphine formulations. ${ }^{34}$

\section{Oxymorphone}

Oxymorphone is a semisynthetic opioid agonist with approximately two to three times greater analgesic potency and a more rapid onset of action compared with morphine..$^{70,71}$ Originally, an ER matrix formulation using the TIMERx (Endo Pharmaceuticals, Chadds Ford, PA, USA) delivery system slowly releases oxymorphone over 12 hours to afford consistent plasma levels with low peak-to-trough fluctuations. Studies suggest a reasonable oral morphine: oxymorphone equianalgesic potency ratio of $2-3: 1 .^{59,67}$ A recently released putative ADF of oxymorphone ER (Opana ER; Endo Pharmaceuticals, Chadds Ford, PA, USA), in which the active drug is embedded in a hard polymer matrix (INTAC; Grünenthal, Aachen, Germany) is currently marketed in the United States. ${ }^{59,72}$ Clinical studies suggest these two oxymorphone ER formulations are bioequivalent and have similar safety profiles. ${ }^{72}$ Modest alcohol consumption (modeled using $240 \mathrm{~mL}$ of $4 \%$ ethanol) along with oxymorphone ER tablets does not appear to have an effect, whereas moderate alcohol use or abuse (modeled using $240 \mathrm{~mL}$ of $20 \%$ and $40 \%$ ethanol, respectively) may produce meaningful consequences. ${ }^{73}$ Coadministration of oxymorphone ER with $20 \%$ or $40 \%$ ethanol increased $\mathrm{C}_{\max }$ levels by an average of $31 \%$ and $70 \%$, respectively, and the median $\mathrm{T}_{\max }$ was shortened by 30 minutes. ${ }^{59,73}$

\section{Hydromorphone}

A new once-daily, oral osmotic pump (OROS; Alza, Mountain View, CA, USA) formulation of the semisynthetic opioid hydromorphone (Exalgo, Mallinckrodt Brand Pharmaceuticals, Hazelwood, MO, USA) was approved in 2010 by the US Food and Drug Administration (FDA).$^{60}$ This ADF provides relatively constant steady-state concentrations over 24 hours, equivalent AUCs, and a 26\% lower $\mathrm{C}_{\max }$ and $43 \%$ higher $\mathrm{C}_{\min }$ compared with an IR hydromorphone formulation. ${ }^{74,75}$ Bioavailability is only minimally affected by food or alcohol. ${ }^{76}$ This formulation has low plasma protein binding and low probability of interfering with the metabolism of other drugs. ${ }^{76,77}$ Research has demonstrated comparable steady-state plasma drug concentrations and bioequivalence between the OROS ER and IR formulations, with substantially smaller peak-to-trough fluctuations associated with OROS ER compared with IR hydromorphone formulations (61\% vs $172 \%$, respectively). ${ }^{74}$ The hard exterior of the tablet has been shown to withstand significant force, minimizing its ability to be intentionally manipulated through biting or chewing. ${ }^{78}$ In addition, after milling the tablet, only $30 \%$ of active ingredient could be recovered, minimizing the appeal of bolus doses through this form of manipulation. ${ }^{78}$ When switching to OROS hydromorphone from morphine sulfate, the relative potency dose ratio is 5:1 (HM:MS). ${ }^{75,79}$

\section{Tapentadol}

Tapentadol has a dual mechanism of action: it is a mu-opioid receptor agonist and a norepinephrine-reuptake inhibitor, with minimal serotonin effects. ${ }^{80,81}$ As a mu-opioid, it has similar abuse liability to the other strong mu-opioids. The synergistic interaction may be particularly beneficial for patients with neuropathic pain, ${ }^{80}$ and limited protein binding minimizes the risk of drug-drug interactions. ${ }^{80}$ An oral ER formulation (Nucynta ER, Janssen Pharmaceuticals, Titusville, NJ, USA) provides a 12-hour duration of effect with comparable analgesia and a favorable gastrointestinal tolerability profile. ${ }^{61,80,82-85}$ Tapentadol has recently had its indication expanded from chronic moderate to severe pain to include neuropathic pain resulting from diabetic peripheral neuropathy. ${ }^{61}$

\section{Oxycodone}

Oxycodone controlled release (OxyContin; Purdue Pharma) is a pure mu-opioid receptor agonist that has an abuse potential similar to that of other strong opioids. ${ }^{62}$ The controlled-release oxycodone formulation provides delivery of oxycodone continuously over a 12-hour period and has high oral bioavailability $(60 \%-87 \%)$ due to low presystemic and/or first-pass metabolism. ${ }^{62}$ Upon repeated dosing in healthy subjects in pharmacokinetic studies, steady-state 
plasma concentrations of oxycodone were achieved within 24-36 hours. $^{62}$

\section{Methadone}

Methadone (Dolophine, Roxane Laboratories, Columbus, $\mathrm{OH}, \mathrm{USA}$; Methadose, Mallinckrodt Brand Pharmaceuticals) is a highly lipophilic synthetic mu-opioid agonist with unique pharmacokinetic and pharmacodynamic properties. ${ }^{63,64,86}$ The relative potency may depend upon the dose of the opioid taken before the switch to methadone, and whether the patient was switching from or to methadone. ${ }^{67}$ Unlike other ER opioids, methadone is an intrinsically long-acting opioid because it has a long and variable half-life, ranging from 12 to 120 hours, compared with 2-4 hours with oral morphine. This has been associated with an elevated risk of overdose deaths, because severe toxicities may not become apparent for 2-5 days. ${ }^{33,86}$ The low cost of methadone may account for the dramatic increases in prescriptions over the past decade. ${ }^{22,87}$ Although methadone represents fewer than $5 \%$ of opioid prescriptions dispensed, it is implicated in one in three opioid-related deaths. ${ }^{87}$ Because of its unpredictable pharmacokinetics, caution should be used when prescribing methadone. $^{13}$

\section{Transdermal formulations}

In addition to the ER oral formulations, two transdermal formulations are available, one containing fentanyl and the other containing buprenorphine. ${ }^{65,66}$ Both fentanyl and buprenorphine are potent synthetic opioids that are highly lipophilic and have a low molecular weight. ${ }^{88,89}$ In addition to possible cutaneous reactions to the patches, patients should be aware that any direct heat to the attached patch - including increases in body temperature (eg, fevers) or elevations in ambient temperatures (eg, hot tubs, heating blankets) - can substantially increase the amount of active drug released. ${ }^{88,90}$

\section{Fentanyl}

The original transdermal fentanyl reservoir formulation has had problems with adhesion and is associated with a risk of drug leakage and greater ease of drug extraction, limiting its use..$^{91,92}$ The newer matrix patch (Duragesic, Janssen Pharmaceuticals) was designed with a reduced drug load: drug-containing droplets are contained within a silicone matrix with a rate-controlling membrane..$^{65,91,92}$ The patch is to be replaced every 72 hours. Comparing reservoir to matrix systems indicates comparable systemic and topical safety profiles, as well as bioequivalent systemic exposures of fentanyl. ${ }^{93}$ However, increased skin temperature, as through exposure to heat, has been associated with greater fentanyl absorption and may increase the risk of overdose. ${ }^{94,95}$ In addition, recent research indicates greater intrasubject and intersubject variability in absorption, metabolism due to genetic polymorphisms, and interference of metabolism associated with concomitant medication use than was previously observed, which has been associated with unpredictable adverse effects, including fatalities. ${ }^{96}$ In general, the matrix patch appears to be less amenable to tampering than the traditional reservoir system: the design of the matrix patch makes it more difficult to extract active drug. Nevertheless, both types of patches contain very high doses of fentanyl both before and after use, increasing the risk for overdose. ${ }^{94}$

\section{Buprenorphine}

Buprenorphine is a semisynthetic derivative of thebaine, and its unique mechanism of action as a partial agonist at the mu-opioid receptor shows a decreased propensity to produce respiratory depression unless combined with other central nervous system (CNS) depressants. ${ }^{89,97}$ In contrast to the other mu-opioid receptor agonists that are Schedule II agents, buprenorphine is considered a Schedule III drug, meaning that it can be used for medical purposes and has a moderate (vs high) addiction potential. Therapeutic efficacy is achieved with daily doses of $0.5-2 \mathrm{mg}$, making it 25-50 times more potent as an analgesic per milligram than morphine. ${ }^{89,98}$ The low-dose transdermal 7-day buprenorphine matrix patch (Butrans, Purdue Pharma), recommended for patients with moderate to severe pain, appears to be efficacious, generally well tolerated, and convenient. ${ }^{66,99-101}$ The formulation provides continuous delivery of buprenorphine to afford generally consistent plasma drug concentrations throughout the 7-day dosing interval. ${ }^{97}$ It does not require dosage adjustments in older patients (aged $\geq 65$ years) and has an adverse-event profile comparable to other opioid analgesics, ${ }^{97}$ although local skin reactions can be therapy-resistant and may be treatmentlimiting. ${ }^{89}$ In an analysis of long-term use, data from a Norwegian Prescription Database study of 13,451 new users of this patch, from its introduction in November 2005 through December 2008, showed that nearly half (44\%) of patients were dispensed only one prescription. ${ }^{102}$

\section{Therapeutic benefits of extended-release opioids}

Among the putative benefits associated with the pharmacokinetic properties of ER formulations are the potential for sustained and consistent analgesia, less end-of-dose 
failure or breakthrough pain, and better consolidated nighttime pain control with less need for nighttime dosing. ${ }^{5,26,27}$ Nearly $89 \%$ of patients with chronic pain report comorbid pain-related sleep disturbance; pain exacerbates sleep problems that can lead to physical and mental symptoms, including depression. ${ }^{26,103-105}$ Although both IR and ER opioid formulations have the potential to improve sleep, IR agents may not provide as much benefit as ER formulations for patients who wake during the night with pain or who have early morning pain. ${ }^{26} \mathrm{ER}$ agents may facilitate more consolidated sleep patterns compared with IR agents. ${ }^{106,107}$ Sleep problems resulting from osteoarthritis-induced chronic pain were qualitatively and quantitatively improved after treatment with a oncedaily ER morphine formulation. ${ }^{108}$ Similarly, a higher percentage of patients with pain receiving a buprenorphine transdermal patch compared with patients receiving a placebo patch reported uninterrupted sleep for durations longer than 6 hours. ${ }^{109}$

Both IR and ER formulations improve QoL measures of mood, social and overall physical function, and work. ${ }^{26}$ However, ER formulations appear to improve treatment responses and afford better patient perceptions of QoL than do IR formulations. ${ }^{107,110} \mathrm{~A}$ recent study under real-world conditions involving once-daily ER morphine sulfate tablets demonstrated significantly reduced pain scores that led to improved sleep and physical functioning among patients with chronic moderate to severe pain over the 3-month study period. ${ }^{65}$ Another study showed that a once-daily ER morphine sulfate formulation was associated with significantly better and earlier improvements in physical function and ability to work than a twice-daily oxycodone formulation. ${ }^{111}$

Less frequent dosing may also facilitate greater treatment adherence. ${ }^{5}$ ER formulations appear to increase adherence and reduce pain-related anxieties. ${ }^{107}$ Good adherence has been associated with improved treatment efficacy in pain relief and QoL. ${ }^{112}$

\section{Clinical practices to promote appropriate choice and use of opioid formulations}

Whether prescribing ER or IR opioid therapy for an individual patient, selecting an appropriate formulation must take into consideration a variety of factors, including patient age, hepatic and renal status, the risk for drug-drug interactions, and the effects of coadministration with alcohol and other CNS depressants (Figure 2). ${ }^{12-14}$

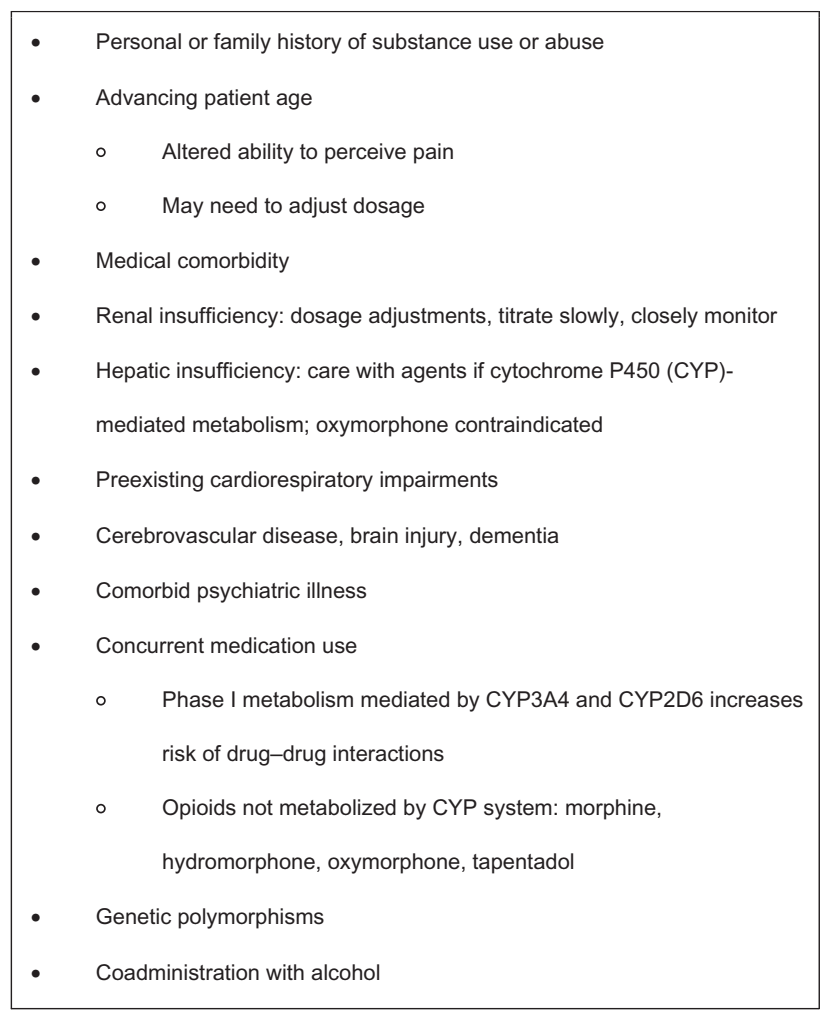

Figure 2 Factors to consider before initiating treatment with an opioid analgesic. ${ }^{12-14}$

\section{Identifying appropriate candidates for extended-release opioid therapy}

Opioids have demonstrated efficacy against most forms of pain. ${ }^{13}$ However, prescription opioids are not appropriate for all patients and all chronic pain conditions. According to labeling by the FDA, modified-release opioids are "for the management of moderate to severe pain when a continuous, around-the-clock analgesic is needed for an extended period of time; they are not intended for intermittent dosing or as an as-needed analgesic." ${ }^{113}$ In addition, the boxed warning on all modified-release prescription opioids highlights the need for proper patient selection, noting that "persons at increased risk for opioid abuse include those with a personal or family history of substance abuse or mental illness. Patients should be assessed for their clinical risks for opioid abuse or addiction prior to being prescribed opioids. All patients receiving opioids should be routinely monitored for signs of misuse, abuse and addiction." 113

\section{Reviewing relevant patient health conditions}

Health conditions such as hepatic or renal impairment and presence of cardiovascular disease, dementia, or 
cerebrovascular conditions can impact opioid effects, and patients should be assessed for these conditions prior to initiating opioids. Older patients, in particular, may be likely to have one or more of these comorbidities. ${ }^{114}$ The slower metabolism of older patients, along with decreased renal and hepatic blood flow and mass, make them particularly vulnerable to adverse events and increased sensitivities to opioid agents. ${ }^{14,76,115,116}$ In addition, this population has a high use of polypharmacy, which may increase the likelihood of drug-drug interactions. ${ }^{117}$ Similarly, older patients experience an elevated risk of respiratory depression, bradycardia, or hypotension with prescription opioid use. ${ }^{114,118,119}$ Patients with existing cardiorespiratory impairment should be monitored very carefully if prescribed opioids. ${ }^{52,114,120}$

Most opioid analgesics or their metabolites - active or inactive - are primarily eliminated in the urine, necessitating dosage adjustments for patients with significant renal impairments. ${ }^{114}$ Clinicians can prescribe opioid analgesics albeit with caution - to patients with renal or hepatic failure, using low doses and slow titration schedules. ${ }^{114,121,122}$ Specific agents, including morphine, codeine, and hydromorphone, should be avoided or used with caution, because of the accumulation of bioactive drug or metabolites, which might result in potential toxicities. ${ }^{59,62,65,114,123-127}$ In patients with renal impairment, accumulation of morphine or codeine can cause severe adverse effects; administration of hydromorphone to patients with chronic renal failure can cause neuroexcitatory symptoms, including pain, cognitive impairments, and seizures. ${ }^{114}$ The high variability in pharmacokinetics associated with methadone leads to recommendations against its use as a first-line agent among older patients.

\section{Reviewing existing medications for interactions}

Research indicates that nearly one in five patients take multiple opioid analgesics: $32 \%$ take more than five concurrent medications, and 21\% take more than ten medications. ${ }^{114,128}$ Polypharmacy has been associated with poor adherence to treatment and increased potential risk of drug-drug interactions. $^{76,129}$

Many prescription opioids undergo phase I metabolism mediated by cytochrome P450 (CYP) enzymes, especially CYP3A4 and CYP2D6. Multiple agents affect 3A4 activity. Fewer affect 2D6, but genetic variations in 2D6 expression may result in altered pharmacokinetics as well. Thus, agents metabolized this way may substantially increase the risk of drug-drug interactions and can influence the efficacy or tolerability of the agent. ${ }^{114,130-133}$ For example, absorption of methadone is mediated by gastric $\mathrm{pH}$ and $\mathrm{P}$-glycoprotein and is metabolized in part by CYP3A4 and CYP2D6, resulting in many potential drug interactions. ${ }^{86}$ Morphine, hydromorphone, oxymorphone, and tapentadol are among the few opioid agents that undergo phase II hepatic metabolism via glucuronidation, bypassing CYP-mediated metabolism and thereby reducing the risk of drug-drug interactions involving the CYP450 system. ${ }^{14,123,133-136}$ However, the metabolites themselves may vary in biologic effect, activity, and potency, and therefore awareness of these pathways alone might not be sufficient in avoiding drug-drug interactions or the consequences of accumulated breakdown products.

\section{Educating patients on alcohol use}

Coadministration of prescription opioids with alcohol or other CNS depressants can exacerbate the respiratory depressant effects of opioids. Concurrent use of specific opioid-delivery systems with alcohol can also result in an increase in the release rate of the opioid, an effect known as "dose dumping," resulting in absorption of a potentially fatal dose of the analgesic. ${ }^{137}$ This phenomenon was observed with an ER formulation of hydromorphone (Palladone CL), leading to the removal of this product from the market. ${ }^{138}$ Variable effects have been observed with an ER formulation of oxymorphone, ${ }^{59,139}$ although a new formulation is being developed that is more resistant to the effects of alcohol. ${ }^{73} \mathrm{On}$ the other hand, alcohol has not been found to alter appreciably the release characteristics of morphine sulfate ER capsules or OROS hydromorphone ER tablets. ${ }^{137,140-142}$ Regardless of the pharmacokinetic effects, warnings concerning the coadministration of any opioid with alcohol are warranted, due to the pharmacodynamic effects and the combination of two CNS depressants.

\section{Collecting complete histories of substance-use behavior}

Balancing the risks and benefits of opioid analgesics, therefore, is essential in the management of pain with opioids. In recent decades, a structured approach to manage risk has been recommended (Figure 3). ${ }^{13,33,143}$ Clinicians can adopt a universal precautions approach, in which all patients who might benefit from prescription opioids undergo a substance-use assessment, using an appropriate minimum level of precaution (Figure 3). ${ }^{13,33,143}$ A number of rapid-assessment tools are amenable for use in the primary care setting, including the Opioid Risk Tool ${ }^{144}$ and the Screener and Opioid Assessment for Patients with Pain. ${ }^{145}$ Patients should be asked in a nonjudgmental manner about current and prior use of licit and 
1. Make a diagnosis with appropriate differential

a. Include comorbid medical illnesses

2. Complete psychological assessment

a. Include psychiatric comorbidities

b. Include risk of addiction

3. Informed consent

4. Treatment agreement (verbal and/or written)

a. Include pain and functional goals

5. Assessment of pain intensity and impact on functioning (preintervention[s])

6. Appropriate trials of opioid therapy (alone or with adjunctive medications)

7. Reassessment of pain intensity and level of function (postintervention)

8. Regular assessment of "four A's" of pain medicine

a. Analgesia (pain relief)

b. Activity (functional goals)

c. Adverse effects

d. Aberrant behavior (and adherence to treatment plan)

9. Periodic reviews

a. Pain diagnosis

b. Comorbid conditions

c. Addictive disorders

10. Documentation

Figure 3 Ten steps of universal precautions in pain medicine. Note: data from Gourlay et al. ${ }^{143}$

illicit drugs, their willingness to see specialists if referred, and their willingness to participate in urine drug testing. Patients with current or a history of drug abuse can be safely treated with opioid analgesics, but typically require more careful monitoring. ${ }^{146}$ However, those patients who demonstrate a high risk for misuse or abuse of opioids might not be appropriate candidates. ${ }^{143}$ The high comorbidity between pain and psychiatric conditions, especially depression, leads to poorer prognoses for both conditions ${ }^{76}$ and might increase the patient's risk for substance abuse or addiction. ${ }^{114,147}$ Clinicians need to continually monitor all patients, regardless of their age, for signs of tolerance, hyperalgesia, or drug abuse. ${ }^{112}$

Given the wide variability in response of patients to different opioids, selecting a specific agent that is effective and well tolerated in a given patient initiating opioid therapy represents yet another challenge. ${ }^{132}$ Specific genetic polymorphisms have been identified that may explain some of this variability (eg, CYP2D6 polymorphisms that result in either rapid or slow drug metabolism can impact both the analgesic response to an opioid and the risk for adverse events), ${ }^{132,148-150}$ but genetic testing is not yet routinely performed. ${ }^{149}$ Accordingly, a trial of several different opioids may be necessary to find the appropriate regimen for an individual patient. In a retrospective chart review of patients with chronic pain initiated on opioid therapy, four opioid rotations were required in order for $80 \%$ of patients (cumulatively) to find an effective and well-tolerated opioid. ${ }^{151}$ Only $36 \%$ of patients responded to the first opioid prescribed; approximately one-third discontinued treatment because of ineffectiveness, and another 30\% because of side effects. ${ }^{151}$

\section{Incorporating regular urine screening}

Urine toxicology screening can be of use in monitoring patients on long-term opioid therapy, ${ }^{152}$ especially those at risk for aberrant behavior. Screening can help improve adherence to therapy by detecting use of prescribed medications, as well as illicit drug use. However, physicians should be aware of the limitations of screening: it is not particularly effective at detecting synthetic opioids, and cross-reactivity between drugs is common. ${ }^{153}$

\section{Planning to address side effects}

Given that side effects frequently cause patients to discontinue opioid therapy, clinicians should assess and treat comorbidities and discontinue as appropriate current medications that contribute to the incidence and severity of side effects. Pharmacological approaches for preventing or treating opioid-induced side effects include symptomatic treatment (eg, antiemetics), switching route of administration, using an opioid-sparing regimen (eg, by addition of a nonsteroidal anti-inflammatory agent), or, as discussed above, switching to an alternative opioid. ${ }^{15}$

\section{Minimizing potential for abuse and diversion}

The abuse liability of opioids has been well established. Opioids have mood-altering and anxiolytic effects that can induce euphoria, especially when plasma drug levels quickly rise. ${ }^{154}$ However, the means of misuse and abuse differ depending upon an individual's drug-use history. Experienced abusers are likely to manipulate the tablets (by crushing, injecting, or snorting) to obtain the greatest or fastest response, whereas less experienced users of prescription opioids are likely to misuse the agents by taking more than the recommended dose or by taking the prescribed dose more frequently than recommended. Consequently, rapid-acting IR formulations can be particularly attractive to experienced abusers. Similarly, the greater amount of active agent in ER 
formulations also makes them attractive to experienced abusers, and it makes these formulations potentially more lethal when abused. However, clinicians should be aware that the vast majority of opioid abuse is through oral use and does not entail tablet manipulation. Both forms of abuse are important to address, albeit through different venues. Conventional abuse of oral tablets can only be addressed through appropriate patient selection, counseling, and monitoring. Drug manufacturers are trying to address abuse through nonoral routes by developing ADFs. In addition, US governmental agencies have developed Risk Evaluation and Mitigation Strategies (REMS) that include, among other strategies, physician education and patient counseling.

\section{Epidemiology of abuse}

In the US, an increasing number of people are misusing prescription opioids..$^{26,155-157}$ The proportion of the US population aged 12 years or over that has ever used prescription pain relievers nonmedically increased from 30 million in 2002 to 35 million in 2010. ${ }^{142}$ Among first-time users of illicit drugs, nonmedical use of prescription pain relievers was second only to marijuana use in 2009. ${ }^{156}$ During the 7-year period between 2002 and 2009, the percentage of young adults aged 18-25 years who misused pain relievers increased from $4.1 \%$ to $4.8 \%$, whereas the percentage who abused cocaine or methamphetamines decreased (from $2.0 \%$ to $1.5 \%$, and from $0.6 \%$ to $0.2 \%$, respectively). ${ }^{156}$ College-age students have the highest prevalence rate of nonmedical use of opioids, which they predominantly obtained from friends or parents. ${ }^{158}$ Abuse is not limited to young adults, and the rate of illicit drug use in adults aged 50-59 years increased from $2.7 \%$ to $5.8 \%$ between 2002 and $2010 .{ }^{156}$ One study suggests that as many as $75 \%$ of patients with pain do not take their prescriptions as prescribed. ${ }^{159}$ The prevalence of addiction in the general population is estimated at $10 \%$; compared with general population samples, the frequency of opioid-use disorders is substantially elevated among patients receiving opioid therapy. ${ }^{160-163}$

Essentially three types of persons abuse or misuse opioid drugs: patients receiving pain medication who also abuse (those who obtain the drug legally for medical use but use it unsafely or in ways not prescribed), recreational drug abusers who obtain the drug illegally for experimentation or to get high, and experienced drug abusers. ${ }^{164}$ Patients with pain typically fall into the first category: their most common means of misuse or abuse is through oral administration, by taking more of the medication at or above the recommended doses using the normal route of administration, or by taking the pills when not in pain. ${ }^{158,165,166}$ This use may be for euphoria, to address other complaints such as anxiety or insomnia (referred to as chemical coping), or for undertreated pain. In contrast, recreational and experienced drug abusers who use opioids may be more likely to alter the drug to change the route of administration. ${ }^{167}$ By altering sustained-release formulations through crushing, snorting, or injecting, a greater portion of the drug can be released than originally intended, to provide the high. ${ }^{154,164,165}$

Identifying patients at elevated risk of progressing from misuse to abuse is imperative. The boxed warning on all prescription-opioid agents highlights that persons with a personal or family history of substance abuse or mental illness (including but not limited to depression) are at increased risk for opioid abuse. ${ }^{113}$ Other potential risk factors include patients with other medical or psychiatric comorbidities and patients with (typically undertreated) significant levels of pain., ${ }^{468,169}$ Aberrant behaviors that suggest misuse or abuse include the use of pain medications for reasons other than pain, evidence of impaired control, compulsive use of the medication, continued use of the opioid agent despite a lack of benefit or a risk of harm, calling for early refills, "losing" prescriptions, or other drug-seeking behaviors, including "doctor shopping." 170

\section{Source of abused prescription opioids}

While the most common motives for opioid abuse include relieving pain, getting high, or experimentation, the most common source of prescription opioids used for nonmedical purposes is from a friend or relative - for free - the majority of whom had originally received the drug as a prescription from one physician. ${ }^{21,154,156,158}$ Fewer than $5 \%$ of persons over age 12 years have obtained a prescription pain reliever from a drug dealer or stranger. ${ }^{21,156}$ Data from the National Epidemiologic Survey on Alcohol and Related Conditions report that prescription-opioid abusers are more likely to be white, male, and college-educated adults. ${ }^{171}$ What is unclear is whether the source of the drug is from a legitimate prescriber or from a source that is or is likely an illegitimate prescribing source (ie, so-called pill mills). Recent arrests in Florida highlight the concern of legitimate pain clinics compared to those solely dealing in the illegal prescribing of opioids. ${ }^{172}$

\section{Pharmacokinetic factors}

Specific drug factors that influence the abuse liability of an agent include its intrinsic pharmacologic activity, its physicochemical properties, and its pharmacokinetic properties (ie, absorption, distribution, biotransformation, 
excretion). ${ }^{173}$ Regarding pharmacokinetic parameters, increases in $\mathrm{C}_{\text {max }}$ and decreases in $\mathrm{T}_{\max }$ have been associated with greater abuse potential of an opioid formulation. ${ }^{164,174}$ The ratio between these two factors $\left(\mathrm{C}_{\max } / \mathrm{T}_{\max }\right)$ has been advanced as a common metric to quantify the abuse potential of a particular formulation, although additional research is necessary to assess the validity of this "abuse quotient." Consistent with findings from the controlled human abuse-liability studies above, veteran abusers indicate that "attractive" agents are those that produce a rapid onset and a sustained duration of effect. ${ }^{175}$ In contrast, unattractive attributes, such as withdrawal effects, slow onset of effect, unpleasantness of administration, and other negative formulation issues, have been associated with reduced abuse potential. ${ }^{175}$

\section{Abuse-deterrent formulations}

Altering formulations to address the problem of overconsumption, either unintentional or intentional, is not currently possible. ${ }^{164}$ However, drug manufacturers are now developing ADFs with the aim of either making opioid analgesics less attractive for nonoral abuse or increasing the consequences of abuse, ultimately to minimize the abuse of opioids among recreational reward-seekers. Current ER opioid formulations maintain constant plasma levels for prolonged periods, thereby reducing the euphoric effects of the drug through less rapid rises in plasma levels and lower peak levels. ${ }^{35,176}$ The current approaches for ADFs or abuse-resistant formulations involve including physical barriers to tampering, agonist-antagonist formulations (eg, adding naltrexone), modified-release formulations, and formulations that are or become highly viscous when attempts are made to defeat the ER mechanisms. ${ }^{154,164,177,178}$ Examples include the currently available OROS hydromorphone ER (Exalgo), the new OxyContin formulation that has tamper-resistant properties, and a number of possible formulations currently under investigation: oxycodone ER in high-viscosity hard gelatin capsules (Remoxy; Pain Therapeutics, Austin, TX, USA); two oral oxycodone formulations using the DETERx tamperresistant formulation (COL-003 and COL-172; Collegium Pharmaceutical, Cumberland, RI, USA); and an oxycodone formulation combined with naltrexone (OxyNal, Elite Pharmaceuticals, Northvale, NJ, USA; PTI-801 or Oxytrex, Pain Therapeutics). ${ }^{21}$

A study that compared the abuse potential of OROS hydromorphone ER with IR hydromorphone among subjects with a history of recreational opioid use showed that the delayed onset of good drug effects and prominent bad drug effects of the OROS ER formulation was likely to decrease its potential for abuse. ${ }^{35}$ The hard outer shell of the OROS hydromorphone ER tablet further minimizes its abuse potential by making the tablet substantially more difficult to manipulate through chewing or biting. ${ }^{78}$ In addition, research indicates that only $50 \%$ of active ingredient was recovered after 24 hours of immersion in water, and only $30 \%$ was recovered after milling. ${ }^{78}$ Another ADF involves embedding pellets of ER morphine sulfate with a sequestered core of naltrexone (MS-sNT, Embeda): naltrexone is released if the capsule is crushed, mitigating any morphine-induced effects. ${ }^{179}$ This formulation is currently not being marketed. There are, as yet, no data establishing an increased efficacy or decreased risk of misuse or abuse with this formulation. ${ }^{180}$

A controlled-release formulation of oxycodone has been associated with less drug-liking than the IR formulation when intact tablets are taken whole, requiring nearly twofoldhigher doses to achieve comparable subjective effects. ${ }^{176}$ In an effort to curb the widespread nonmedical use and abuse of controlled-release oxycodone, the FDA approved a new tamper-resistant formulation in $2010 .{ }^{181}$ The controlledrelease polymer system of the new formulation makes the tablet more difficult to crush, chew, dissolve, or melt, potentially discouraging injection and inhalation. ${ }^{20,181}$ Recent data from 103 opioid-dependent patients entering treatment programs in the United States showed that reporting of controlled-release oxycodone as the primary drug of abuse decreased from $35.6 \%$ of respondents before release of the new formulation to $12.8 \% 21$ months later $(P<0.001),{ }^{20}$ supporting the utility of tamper-resistant properties in curbing abuse. A waterinsoluble oral formulation of oxycodone ER is also currently in development. Research suggests this formulation (either whole or chewed) has a significantly lower abuse potential on a drug-liking subscale compared with either oxycodone ER or oxycodone IR, when manipulated. ${ }^{36}$

In summary, ADFs are an incremental improvement that may decrease certain forms of abuse involving tablet manipulation. However, because oral abuse is more common, it is important for clinicians to adhere to best-practice guidelines for prescribing opioids, which include stratifying patients according to risk, counseling patients about the risks of their medications, and periodically monitoring and reassessing patients for signs of misuse or abuse. Unfortunately, it is not possible for ADFs to fully address the problems of abuse, misuse, or diversion. While these formulations may offer additional deterrence, clinicians should not have a false sense of security associated with ADFs. 


\section{Risk Evaluation and Mitigation Strategies}

The goal of REMS is to ensure that a drug's benefits outweigh any risks in clinical practice. ${ }^{21}$ To address the escalating problem of prescription-drug abuse, the FDA has proposed a prescription-drug abuse-prevention plan that includes opioid REMS, patient-provider agreements and guidelines, an increased use of prescription-drug monitoring programs, and establishing regulations for controlled-substance prescription drugs. ${ }^{182,183}$ Toward this end, physicians may be required to undergo mandatory education, provide patient education, and potentially enroll patients into registries. ${ }^{155,182}$ A government blueprint has been created that emphasizes that health-care professionals have a responsibility to ensure the safe and effective use of ER opioid analgesics, and that providers are knowledgeable about these agents. ${ }^{113}$

The four main components of this blueprint comprise patient screening, initiating and discontinuing treatment, managing opioid treatment (including goal-setting), and counseling patients about appropriate opioid use. When assessing patients for possible treatment with ER opioid analgesics, clinicians are recommended to assess the potential risks against the potential benefits of prescription-opioid use, and to determine the individual patient's risk of abuse and tolerance for opioids.

Physicians should be aware of current regulations and appropriate dose selection and titration of opioid therapies. This includes familiarity with converting from IR to ER formulations, as well as equianalgesic dosing concepts. While managing patients on opioid therapy, clinicians must focus on appropriate goal-setting and integrating patient-provider agreements and prescription-drug monitoring programs. In addition, clinicians should be familiar with how to manage adverse events and tolerance, and should continue to monitor the patient's symptoms and any underlying medical conditions. During chronic treatment, physicians should periodically assess continuing requirements for opioid analgesia on an individual patient basis.

Of particular importance is the need to counsel patients and their caregivers adequately regarding the safe use, storage, and disposal of ER opioids. Proper disposal of unused medicine is essential for preventing unintentional overdose. Although most medications can be disposed of in the household trash (after mixing them with an unpalatable substance such as coffee grounds and sealing the mixture in a bag) or taken to drug "take-back" programs in the community, for controlled substances such as strong ER opioids, the FDA recommends flushing the unused medication to reduce risk of exposure to patients' household members. ${ }^{184}$

These processes embody many best practices recommended by numerous authors for the safe use of opioids. ${ }^{13,143}$ However, the degree to which REMS and other opioidprescribing guidelines will impact the upward trend in opioid prescribing is unknown.

\section{Conclusion}

Chronic pain is a substantial problem that is likely to continue growing with the aging of the American population. It is currently underdiagnosed and undertreated, leading to substantial burdens on both the personal and the national level. Appropriate management typically includes the use of prescription-opioid analgesics; however, many clinicians remain hesitant and confused about the proper use of opioid analgesics. In addition to proper patient selection and ongoing monitoring, new formulations using ER technologies and other abuse-deterrent approaches may help combat the growing risk of abuse or misuse.

\section{Acknowledgments}

Technical editorial and medical writing support for the preparation of this manuscript was provided by Lynne Kolton Schneider, PhD, and Synchrony Medical Communications, LLC, West Chester, PA, USA. Funding for this support was provided by Mallinckrodt Inc, the Pharmaceuticals business of Covidien, Hazelwood, MO, USA.

\section{Disclosure}

Dr Brennan reports serving as a consultant or speaker for Apricus Biosciences, Covidien Pharmaceuticals, Eli Lilly, Endo Pharmaceuticals, Forest Pharmaceuticals, Insys Therapeutics, Johnson and Johnson, Purdue Pharma, and Teva Pharmaceuticals.

\section{References}

1. Institute of Medicine of the National Academies. Relieving Pain in America: A Blueprint for Transforming Prevention, Care, Education, and Research. Washington: IOM; 2011. Available from: http://www. iom.edu/relievingpain. Accessed October 12, 2011.

2. Croft P, Blyth FM, van der Windt D. The global occurrence of chronic pain: an introduction. In: Croft P, Blyth FM, van der Windt D, editors. Chronic Pain Epidemiology: From Aetiology to Public Health. Oxford: Oxford University Press; 2010:9-18.

3. Breivik H, Collett B, Ventafridda V, Cohen R, Gallacher D. Survey of chronic pain in Europe: prevalence, impact on daily life, and treatment. Eur J Pain. 2006;10:287-333.

4. Cicero TJ, Surratt HL, Kurtz S, Ellis MS, Inciardi JA. Patterns of prescription opioid abuse and comorbidity in an aging treatment population. $J$ Subst Abuse Treat. 2012;42:87-94. 
5. Nicholson B. Benefits of extended-release opioid analgesic formulations in the treatment of chronic pain. Pain Pract. 2008;9:71-81.

6. Gureje O, Von Korff M, Simon GE, Gater R. Persistent pain and wellbeing: a World Health Organization study in primary care. JAMA. 1998;280:147-151.

7. Gureje O, Simon GE, Von Korff M. A cross-national study of the course of persistent pain in primary care. Pain. 2001;92:195-200.

8. Breuer B, Cruciani R, Portenoy RK. Pain management by primary care physicians, pain physicians, chiropractors, and acupuncturists: a national survey. South Med J. 2010;103:738-747.

9. Kuehn BM. Opioid prescriptions soar: increase in legitimate use as well as abuse. JAMA. 2007;297:249-251.

10. Moskovitz BL, Benson CJ, Patel AA, et al. Analgesic treatment for moderate-to-severe acute pain in the United States: patient perspectives in the Physicians Partnering Against Pain (P3) survey. J Opioid Manag. 2011;7:277-286.

11. Manchikanti L, Singh V, Datta S, Cohen SP, Hirsch JA. Comprehensive review of epidemiology, scope, and impact of spinal pain. Pain Physician. 2009;12:E35-E70.

12. Manchikanti L, Abdi S, Atluri S, et al. American Society of Interventional Pain Physicians (ASIPP) guidelines for responsible opioid prescribing in chronic non-cancer pain: Part 2 - guidance. Pain Physician. 2012;15:S67-S116.

13. Chou R, Fanciullo GJ, Fine PG, et al. Clinical guidelines for the use of chronic opioid therapy in chronic noncancer pain. J Pain. 2009;10: 113-130.

14. American Geriatrics Society Panel on the Pharmacological Management of Persistent Pain in Older Persons. Pharmacological management of persistent pain in older persons. Pain Med. 2009;10:1062-1083.

15. McNicol E. Opioid side effects and their treatment in patients with chronic cancer and noncancer pain. J Pain Palliat Care Pharmacother. 2008;22:270-281.

16. Chan BKB, Tam LK, Wat CY, Chung YF, Tsui SL, Cheung CW. Opioids in chronic non-cancer pain. Expert Opin Pharmacother. 2011; 12:705-720.

17. Manchikanti L, Ailinani H, Koyyalagunta D, et al. A systematic review of randomized trials for long-term opioid management for chronic noncancer pain. Pain Physician. 2011;14:91-121.

18. Stannard CF. Opioids for chronic pain: promise and pitfalls. Curr Opin Support Palliat Care. 2011;5:150-157.

19. Angst MS, Chu LF, Tingle MS, Shafer SL, Clark JD, Drover DR. No evidence for the development of acute tolerance to analgesic, respiratory depressant and sedative opioid effects in humans. Pain. 2009;142:17-26.

20. Cicero TJ, Ellis MS. Effect of abuse-deterrent formulation of OxyContin. N Engl J Med. 2012;367:187-189.

21. Webster L, St Marie B, McCarberg B, Passik SD, Panchal SJ, Voth E. Current status and evolving role of abuse-deterrent opioids in managing patients with chronic pain. J Opioid Manag. 2011;7:235-245.

22. Leverence RR, Williams RL, Potter M, et al. Chronic non-cancer pain: a siren for primary care - a report from the Primary Care Multiethnic Network (PRIME Net). J Am Board Fam Med. 2011;24:551-561.

23. Fisch MJ, Lee JW, Weiss M, et al. Prospective, observational study of pain and analgesic prescribing in medical oncology outpatients with breast, colorectal, lung, or prostate cancer. J Clin Oncol. 2012;30: 1980-1988

24. Pappagallo M. Incidence, prevalence, and management of opioid bowel dysfunction. Am J Surg. 2001;182:11S-18S.

25. Trescot AM, Datta S, Lee M, Hansen H. Opioid pharmacology. Pain Physician. 2008;11:S133-S153.

26. Argoff CE, Silvershein DI. A comparison of long- and short-acting opioids for the treatment of chronic noncancer pain: tailoring therapy to meet patient needs. Mayo Clin Proc. 2009;84:602-612.

27. Portenoy RK, Sciberras A, Eliot L, Loewen G, Butler J, Devane J. Steady-state pharmacokinetic comparison of a new, extended-release, once daily morphine formulation, Avinza, and a twice-daily controlledrelease morphine formulation in patients with chronic moderate-tosevere pain. J Pain Symptom Manage. 2002;23:292-300.
28. Caldwell JR, Hale ME, Boyd RE, et al. Treatment of osteoarthritis pain with CR oxycodone or fixed combination oxycodone plus acetaminophen added to nonsteroidal antiinflammatory drugs: a double blind, randomized, multicenter, placebo controlled trial. J Rheumatol. 1999;26:862-869.

29. Hagen NA, Thirlwell M, Eisenhoffer J, Quigley P, Harsanyi Z, Darke A. Efficacy, safety, and steady-state pharmacokinetics of once-a-day controlled-release morphine (MS Contin XL) in cancer pain. J Pain Symptom Manage. 2005;29:80-90.

30. Carson S, Thakurta S, Low A, Smith B, Chou R. Drug class review. Long-acting opioid analgesics. Final update 6 report. Portland (OR): Oregon Health and Science University; 2011. Available from: http:// www.ncbi.nlm.nih.gov/books/NBK62335. Accessed September 14, 2012.

31. Coluzzi F, Mattia C. Oxycodone. Pharmacological profile and clinical data in chronic pain management. Minerva Anestesiol. 2005;71:451-460.

32. Bohnert AS, Valenstein M, Bair MJ, et al. Association between opioid prescribing patterns and opioid overdose-related deaths. JAMA. 2011;305:1315-1321.

33. Fine PG, Mahajan G, McPherson ML. Long-acting opioids and shortacting opioids: appropriate use in chronic pain management. Pain Med. 2009;10 Supp1 2:S79-S88.

34. Gourlay GK. Sustained relief of chronic pain. Pharmacokinetics of sustained release morphine. Clin Pharmacokinet. 1998;35:173-190.

35. Shram MJ, Sathyan G, Khanna S, et al. Evaluation of the abuse potential of extended release hydromorphone versus immediate release hydromorphone. J Clin Psychopharmacol. 2010;30:25-33.

36. Setnik B, Roland CL, Cleveland JM, Webster L. The abuse potential of Remoxy, an extended-release formulation of oxycodone, compared with immediate- and extended-release oxycodone. Pain Med. 2011;12:618-631.

37. Duensing L, Eksterowicz N, Macario A, Brown M, Stern L, Ogbonnaya A. Patient and physician perceptions of treatment of moderate-to-severe chronic pain with oral opioids. Curr Med Res Opin. 2010;26:1579-1585.

38. Hale M, Khan A, Kutch M, Li S. Once-daily OROS hydromorphone ER compared with placebo in opioid-tolerant patients with chronic low back pain. Curr Med Res Opin. 2010;26:1505-1518.

39. Gordon A, Callaghan D, Spink D, et al. Buprenorphine transdermal system in adults with chronic low back pain: a randomized, doubleblind, placebo-controlled crossover study, followed by an open-label extension phase. Clin Ther. 2010;32:844-860.

40. Wild JE, Grond S, Kuperwasser B, et al. Long-term safety and tolerability of tapentadol extended release for the management of chronic low back pain or osteoarthritis pain. Pain Pract. 2010;10:416-427.

41. Friedmann N, Klutzaritz V, Webster L. Long-term safety of Remoxy (extended-release oxycodone) in patients with moderate to severe chronic osteoarthritis or low back pain. Pain Med. 2011;12:755-760.

42. Wallace M, Thipphawong J. Open-label study on the long-term efficacy, safety, and impact on quality of life of OROS hydromorphone ER in patients with chronic low back pain. Pain Med. 2010;11:1477-1488.

43. Pergolizzi J, Alon E, Baron R, et al. Tapentadol in the management of chronic low back pain: a novel approach to a complex condition? J Pain Res. 2011;4:203-210.

44. Chao J. Retrospective analysis of Kadian (morphine sulfate sustainedrelease capsules) in patients with chronic, nonmalignant pain. Pain Med. 2005;6:262-265.

45. Matsumoto AK, Babul N, Ahdieh H. Oxymorphone extended-release tablets relieve moderate to severe pain and improve physical function in osteoarthritis: results of a randomized, double-blind, placebo- and active-controlled phase III trial. Pain Med. 2005;6:357-366.

46. Gibofsky A, Barkin RL. Chronic pain of osteoarthritis: considerations for selecting an extended-release opioid analgesic. Am J Ther. 2008:15:241-255.

47. Katz N, Sun S, Johnson F, Stauffer J. AOL-01 (morphine sulfate and naltrexone hydrochloride) extended-release capsules in the treatment of chronic pain of osteoarthritis of the hip or knee: pharmacokinetics, efficacy, and safety. J Pain. 2010;11:303-311. 
48. Fashner J, Bell AL. Herpes zoster and postherpetic neuralgia: prevention and management. Am Fam Physician. 2011;83:1432-1437.

49. Moulin DE, Richarz U, Wallace M, Jacobs A, Thipphawong J. Efficacy of the sustained-release hydromorphone in neuropathic pain management: pooled analysis of three open-label studies. J Pain Palliat Care Pharmacother. 2010;24:200-212.

50. Hermanns K, Junker U, Nolte T. Prolonged-release oxycodone/naloxone in the treatment of neuropathic pain - results from a large observational study. Expert Opin Pharmacother. 2012;13:299-311.

51. Victor TW, Alvarez NA, Gould E. Opioid prescribing practices in chronic pain management: guidelines do not sufficiently influence clinical practice. J Pain. 2009;10:1051-1057.

52. Sloan PA, Barkin RL. Oxymorphone and oxymorphone extended release: a pharmacotherapeutic review. J Opioid Manag. 2008;4:131-144.

53. Facts and Comparisons [homepage on the Internet]. Available from: http://www.factsandcomparisons.com/index.aspx. St Louis: Wolters Kluwer Health. Accessed December 29, 2012.

54. King Pharmaceuticals. Avinza (morphine sulfate extendedrelease capsules): US prescribing information. Bristol (TN): King Pharmaceuticals; 2008.

55. King Pharmaceuticals. Embeda (morphine sulfate and naltrexone hydrochloride) extended-release capsules: US prescribing information. Bristol (TN): King Pharmaceuticals; 2012.

56. Actavis Elizabeth. Kadian (morphine sulfate) extended-release capsules: US prescribing information. Morristown (NJ): Actavis Elizabeth; 2012.

57. Purdue Pharma. MS Contin (morphine sulfate controlled-release) tablets: US prescribing information. Stamford (CT): Purdue Pharma; 2009.

58. Xanodyne Pharmaceuticals. Oramorph SR (morphine sulfate) tablets: US prescribing information. Newport (KY): Xanodyne Pharmaceuticals; 2006.

59. Endo Pharmaceuticals. Opana ER (oxymorphone hydrochloride) extended-release tablets: US prescribing information. Chadds Ford (PA): Endo Pharmaceuticals; 2012.

60. Mallinckrodt Brand Pharmaceuticals. Exalgo (hydromorphone hydrochloride) extended-release tablets: US prescribing information. Hazelwood (MO): Mallinckrodt Brand Pharmaceuticals; 2012.

61. Janssen Pharmaceuticals. Nucynta ER (tapentadol) extended-release oral tablets: US prescribing information. Titusville (NJ): Janssen Pharmaceuticals; 2012.

62. Purdue Pharma. OxyContin (oxycodone hydrochloride controlledrelease) tablets: US prescribing information. Stamford (CT): Purdue Pharma; 2012.

63. Roxane Laboratories. Dolophine (methadone hydrochloride) tablets: US prescribing information. Columbus (OH): Roxane Laboratories; 2012.

64. Mallinckrodt Brand Pharmaceuticals. Methadose oral tablets (methadone hydrochloride tablets USP): US prescribing information. Hazelwood (MO): Mallinckrodt Brand Pharmaceuticals; 2012.

65. Janssen Pharmaceuticals. Duragesic (fentanyl transdermal system): US prescribing information. Titusville (NJ): Janssen Pharmaceuticals; 2012.

66. Purdue Pharma. Butrans (buprenorphine) transdermal system: US prescribing information. Stamford (CT): Purdue Pharma; 2012.

67. Knotkova H, Fine PG, Portenoy RK. Opioid rotation: the science and the limitations of the equianalgesic dose table. J Pain Symptom Manage. 2009;38:426-439.

68. Adams EH, Chwiecko P, Ace-Wagoner Y, et al. A study of Avinza (morphine sulfate extended-release capsules) for chronic moderate-tosevere noncancer pan conducted under real-world treatment conditions the ACCPT Study. Pain Pract. 2006;6:254-264.

69. Caldwell JR, Rapoport RJ, Davis JC, et al. Efficacy and safety of a once-daily morphine formulation in chronic, moderate-to-severe osteoarthritis pain: results from a randomized, placebo-controlled, double-blind trial and an open-label extension trial. J Pain Symptom Manage. 2002;23:278-291.

70. Matsumoto AK. Oral extended-release oxymorphone: a new choice for chronic pain relief. Expert Opin Pharmacother. 2007;8: $1515-1527$.
71. Hale ME, Dvergsten C, Gimbel J. Efficacy and safety of oxymorphone extended release in chronic low back pain: results of a randomized, double-blind, placebo- and active-controlled phase III study. J Pain. 2005;6:21-28.

72. Benedek IH, Jobes J, Xiang Q, Fiske WD. Bioequivalence of oxymorphone extended release and crush-resistant oxymorphone extended release. Drug Design Devel Ther. 2011;5:455-463.

73. Fiske WD, Jobes J, Xiang Q, Chang SC, Benedek IH. The effects of ethanol on the bioavailability of oxymorphone extended-release tablets and oxymorphone crush-resistant extended-release tablets. J Pain. 2012; 13:90-99.

74. Moore KT, St-Fleur D, Marricco NC, et al. Steady-state pharmacokinetics of extended-release hydromorphone (OROS hydromorphone): a randomized study in healthy volunteers. J Opioid Manag. 2010;6:351-358.

75. Wallace M, Rauck RL, Moulin D, Thipphawong J, Khanna S, Tudor IC. Once-daily OROS hydromorphone for the management of chronic nonmalignant pain: a dose-conversion and titration study. Int $J$ Clin Pract. 2007;61:1671-1676.

76. Lussier D, Richarz U, Finco G. Use of hydromorphone, with particular reference to the OROS formulation, in the elderly. Drugs Aging. 2010;27:327-335.

77. Sathyan G, Xu E, Thipphawong J, Gupta SK. Pharmacokinetic investigation of dose proportionality with a 24-hour controlled-release formulation of hydromorphone. BMC Clin Pharmacol. 2007;7:3.

78. Pande P, Hines JW, Brogran AP. Tamper-resistant properties of once-daily hydromorphone ER (OROS hydromorphone ER). Paper presented at the American Pain Society 30th Annual Scientific Meeting; May 19-21, 2011; Austin, USA.

79. Wallace M, Rauck RL, Moulin D, Thipphawong J, Khanna S, Tudor IC. Conversion from standard opioid therapy to once-daily oral extendedrelease hydromorphone in patients with chronic cancer pain. J Internat Med Res. 2008;36:343-352.

80. Hartrick CT, Rozek RJ. Tapentadol in pain management: a mu-opioid receptor agonist and noradrenaline reuptake inhibitor. CNS Drugs. 2011;25:359-370.

81. Hartrick CT, Rodriguez Hernandez JR. Tapentadol for pain: a treatment evaluation. Expert Opin Pharmacother. 2012;13:283-286.

82. Riemsma R, Forbes C, Harker J, et al. Systematic review of tapentadol in chronic severe pain. Curr Med Res Opin. 2011;27:1907-1930.

83. Vadivelu N, Timchenko A, Huang Y, Sinatra R. Tapentadol extended-release for treatment of chronic pain: a review. J Pain Res. 2011;4:211-218.

84. Etropolski M, Kelly K, Okamoto A, Rauschkolb C. Comparable efficacy and superior gastrointestinal tolerability (nausea, vomiting, constipation) of tapentadol compared with oxycodone hydrochloride. Adv Ther. 2011;28:410-417.

85. Cepeda MS, Sutton A, Weinstein R, Kim M. Effect of tapentadol extended release on productivity: results from an analysis combining evidence from multiple sources. Clin J Pain. 2012;28:8-13.

86. Toombs JD, Kral LA. Methadone treatment for pain states. Am Fam Physician. 2005;71:1353-1358.

87. Webster LR, Cochella S, Dasgupta N, et al. An analysis of the root causes for opioid-related overdose deaths in the United States. Pain Med. 2011;12 Suppl 2:S26-S35.

88. Muijsers RBR, Wagstaff AJ. Transdermal fentanyl: an updated review of its pharmacological properties and therapeutic efficacy in chronic cancer pain control. Drugs. 2001;61:2289-2307.

89. Hans G, Robert D. Transdermal buprenorphine - a critical appraisal of its role in pain management. $J$ Pain Res. 2009;2:117-134.

90. Nelson L, Schwaner R. Transdermal fentanyl: pharmacology and toxicology. J Med Toxicol. 2009;5:230-241.

91. Hair PI, Keating GM, McKeage K. Transdermal matrix fentanyl membrane patch (Matrifen) in severe cancer-related chronic pain. Drugs. 2008;68:2001-2009.

92. Marier J-F, Lor M, Morin J, et al. Comparative bioequivalence study between a novel matrix transdermal delivery system of fentanyl and a commercially available reservoir formulation. Br J Clin Pharmacol. 2006;63:121-124. 
93. Moore KT, Adams HD, Natarajan J, Ariyawansa J, Richards HM. Bioequivalence and safety of a novel fentanyl transdermal matrix system compared with a transdermal reservoir system. J Opioid Manag. 2011;7:99-107.

94. [No authors listed]. Fentanyl patches: preventable overdose. Prescrire Int. 2010;19:22-25.

95. Moore KT, Sathyan G, Richarz U, Natarajan J, Vandenbossche J. Randomized 5-treatment crossover study to assess the effects of external heat on serum fentanyl concentrations during treatment with transdermal fentanyl systems. J Clin Pharmacol. 2011;52:1174-1185.

96. Cole JM, Best BM, Pesce AJ. Variability of transdermal fentanyl metabolism and excretion in pain patients. J Opioid Manag. 2010;6: 29-39.

97. Plosker GL. Buprenorphine 5, 10, and 20 micrograms/h transdermal patch: a review of its use in the management of chronic non-malignant pain. Drugs. 2011;71:2491-2509.

98. Cowan A, Lewis JW, Macfarlane IR. Agonist and antagonist properties of buprenorphine: a new antinociceptive agent. Br J Pharmacol. 1977;60:537-545.

99. Schutter U, Ritzdorf I, Heckes B. The transdermal 7-day buprenorphine patch - an effective and safe treatment of pain if tramadol or tilidate/ naloxone is insufficient. Results of a non-interventional study. $M M W$ Fortschr Med. 2010;152 Suppl 2:62-69. German.

100. Steiner D, Munera C, Hale M, Ripa S, Landau C. Efficacy and safety of buprenorphine transdermal system (BTDS) for chronic moderate to severe low back pain: a randomized, double-blind study. J Pain. 2011;12:1163-1173.

101. Steiner DJ, Sitar S, Wen W, et al. Efficacy and safety of the sevenday buprenorphine transdermal system in opiate-naïve patients with moderate to severe chronic low back pain: an enriched, randomized, double-blind, placebo-controlled study. J Pain Symptom Manage. 2011;42:903-917.

102. Nordbo A, Skurtveit S, Borchgrevink PC, Kaasa S, Fredheim OM. Low-dose transdermal buprenorphine-long-term use and co-medication with other potentially addictive drugs. Acta Anaesthesiol Scand. 2012; 56:88-94.

103. McCracken LM, Iverson GL. Disrupted sleep patterns and daily functioning in patients with chronic pain. Pain Res Manag. 2002;7: 75-79.

104. Kosinski M, Jaganap C, Gajria K, Schein J, Freedman J. Pain relief and pain-related sleep disturbance with extended-release tramadol in patients with osteoarthritis. Curr Med Res Opin. 2007;23: 1615-1626.

105. Tang NK, Wright KJ, Salkovskis PM. Prevalence and correlates of clinical insomnia co-occurring with chronic back pain. J Sleep Res. 2007;16:85-95.

106. Binsfeld H, Szczepanski L, Waechter S, Richarz U, Sabatowski R. A randomized study to demonstrate noninferiority of once-daily OROS hydromorphone with twice-daily sustained-release oxycodone for moderate to severe chronic noncancer pain. Pain Pract. 2010;10:404-415.

107. Rauck RL. What is the case for prescribing long-acting opioids over short-acting opioids for patients with chronic pain? A critical review. Pain Pract. 2009;9:468-479.

108. Rosenthal M, Moore P, Groves E, et al. Sleep improves when patients with chronic OA pain are managed with morning dosing of once a day extended-release morphine sulfate (Avinza): findings from a pilot study. J Opioid Manag. 2007;3:145-154.

109. Sittl R. Transdermal buprenorphine in the treatment of chronic pain. Expert Rev Neurother. 2005;5:315-323.

110. Kornick CA, Santiago-Palma J, Moryl N, Payne R, Obbens EA. Benefit-risk assessment of transdermal fentanyl for the treatment of chronic pain. Drug Saf. 2003;26:951-973.

111. Rauck RL, Bookbinder SA, Bunker TR, et al. A randomized, openlabel, multicenter trial comparing once-a-day Avinza (morphine sulfate extended-release capsules) versus twice-a-day OxyContin (oxycodone hydrochloride controlled-release tablets) for the treatment of chronic, moderate to severe low back pain: improved physical functioning in the ACTION trial. J Opioid Manag. 2007;3:35-43.
112. Graziottin A, Gardner-Nix J, Stumpf M, Berliner MN. Opioids: how to improve compliance and adherence. Pain Pract. 2011;11:574-581.

113. US Food and Drug Administration. Risk evaluation and mitigation strategies (REMS) for extended-release and long-acting opioids. 2012. Available from: http://www.fda.gov/downloads/Drugs/ DrugSafety/PostmarketDrugSafetyInformationforPatientsandProviders/ UCM311290.pdf. Accessed November 21, 2012.

114. Smith H, Bruckenthal P. Implications of opioid analgesia for medically complicated patients. Drugs Aging. 2010;27:417-433.

115. Dosa DM, Dore DD, Mor V, Teno JM. Frequency of long-acting opioid analgesic initiation in opioid-naïve nursing home residents. J Pain Symptom Manage. 2009;38:515-521.

116. Razaq M, Balicas M, Mankan N. Use of hydromorphone (Dilaudid) and morphine for patients with hepatic and renal impairment. Am J Ther. 2007;14:414-416.

117. Pergolizzi JV Jr, Labhsetwar SA, Puenpatom RA, Joo S, Ben-Joseph RH, Summers KH. Prevalence of exposure to potential CYP450 pharmacokinetic drug-drug interactions among patients with chronic low back pain taking opioids. Pain Pract. 2011;11:230-239.

118. Peacock WF, Hollander JE, Diercks DB, et al. Morphine and outcomes in acute decompensated heart failure: an ADHERE analysis. Emerg Med J. 2008;25:205-209.

119. Gruber EM, Tschernko EM. Anaesthesia and postoperative analgesia in older patients with chronic obstructive analgesia in older patients with chronic obstructive pulmonary disease: special considerations. Drugs Aging. 2003;20:347-360.

120. Bellville JW, Escarraga LA, Wallenstein SL, et al. Relative respiratory depressant effects of oxymorphone (Numorphan) and morphine. Anesthesiology. 1960;21:397-400.

121. Murtagh FE, Chai MO, Donohoe P, et al. The use of opioid analgesia in end-stage renal disease patients managed without dialysis: recommendations for practice. J Pain Palliat Care Pharmacother. 2007;21:5-16.

122. Tegeder I, Lotsch J, Geisslinger G. Pharmacokinetics of opioids in liver disease. Clin Pharmacokinet. 1999;37:17-40.

123. Purdue Pharma. Dilaudid (hydromorphone hydrochloride) oral liquid and tablets: US prescribing information. Stamford (CT): Purdue Pharma; 2008.

124. Wolff J, Bigler D, Christensen CB, et al. Influence of renal function on the elimination of morphine and morphine glucoronides. Eur J Clin Pharmacol. 1988;34:353-357.

125. Babul N, Durke AC, Hagen N. Hydromorphone metabolite accumulation in renal failure. J Pain Symptom Manage. 1995;10:184-186.

126. Guay DR, Awni WM, Findlay JW, et al. Phamacokinetics and pharmacodynamics of codeine in end-stage renal disease. Clin Pharmacol Ther. 1988;43:63-71.

127. Barkin RL. Extended-release tramadol (Ultram ER): a pharmacotherapeutic, pharmacokinetic, and pharmacodynamics focus on effectiveness and safety in patients with chronic/persistent pain. Am J Ther. 2008;15:157-166.

128. Parsells Kelly J, Cook SF, Kaufman DW, et al. Prevalence and characteristics of opioid use in the US adult population. Pain. 2008;138: 507-513.

129. Jansà M, Hernández $\mathrm{C}$, Vidal $\mathrm{M}$, et al. Multidimensional analysis of treatment adherence in patients with multiple chronic conditions. A cross-sectional study in a tertiary hospital. Patient Educ Couns. 2010;81:161-168.

130. Foster A, Mobley E, Wang Z. Complicated pain management in a CYP4502D6 poor metabolizer. Pain Pract. 2007;7:352-356.

131. Susce MT, Murray-Carmichael E, De Leon J. Response to hydrocodone, codeine and oxycodone in a CYP2D6 poor metabolizer. Prog Neuropsychopharmacol Biol Psychiatry. 2005;30:1356-1358.

132. Smith HS. Opioid metabolism. Mayo Clin Proc. 2009;84:613-624.

133. Adams M, Pieniaszek HJ Jr, Gammaitoni AR, et al. Oxymorphone extended release does not affect CYP2C9 or CCYP3A4 metabolic pathways. J Clin Pharmacol. 2005;45:337-345.

134. Coffman BL, Rios GR, King CD, et al. Human UGT287 catalyzes morphine glucuronidation. Drug Metab Dispos. 1997;25: $1-4$. 
135. De Wildt SN, Kearns GL, Leeder JS, et al. Glucoronidation in humans: pharmacogenetic and developmental aspects. Clin Pharmacokinet. 1999;36:439-452.

136. Sinatra R. Opioid analgesics in primary care: challenges and new advances in the management of noncancer pain. J Am Board Fam Med. 2006;19:165-177.

137. Sathyan G, Sivakumar K, Thipphawong J. Pharmacokinetic profile of a 24-hour controlled-release OROS formulation of hydromorphone in the presence of alcohol. Curr Med Res Opin. 2008;24:297-305.

138. US Food and Drug Administration. FDA alert. Alcohol-Palladone interaction. Available from: http://www.fda.gov/Drugs/DrugSafety/PostmarketDrugSafetyInformationforPatientsandProviders/ ucm129288.htm. Accessed January 28, 2013.

139. Walden M, Nicholls FA, Smith KJ, Tucker GT. The effect of ethanol on the release of opioids from oral prolonged-release preparations. Drug Devel Indust Pharm. 2007;33:1101-1111.

140. Barkin RL, Shirazi D, Kinzler E. Effect of ethanol on the release of morphine sulfate from Oramorph SR tablets. Am J Ther. 2009;16: $482-486$.

141. Johnson F, Wagner G, Sun S, Stauffer J. Effect of concomitant ingestion of alcohol on the in vivo pharmacokinetics of Kadian (morphine sulfate extended-release) capsules. J Pain. 2008;9:330-336.

142. Guay DR. Oral hydromorphone extended-release. Consult Pharm. 2010;25:816-828.

143. Gourlay DL, Heit HA, Almahrezi A. Universal precautions in pain medicine: a rational approach to the treatment of chronic pain. Pain Med. 2005;6:107-112.

144. Webster LR, Webster RM. Predicting aberrant behaviors in opioidtreated patients: preliminary validation of the Opioid Risk Tool. Pain Med. 2005;696:432-442.

145. Butler SF, Budman SH, Fernandez KC, Fanciullo GJ, Jamison RN. Cross-validation of a screener to predict opioid misuse in chronic pain patients (SOAPP-R). J Addict Med. 2009;3:66-73.

146. Passik SD, Kirsh KL, Whitcomb L, et al. A new tool to assess and document pain outcomes in chronic pain patients receiving opioid therapy. Clin Ther. 2004;26:552-561.

147. Edlund MJ, Steffick D, Hudson T, et al. Risk factors for clinically recognized opioid abuse and dependence among veterans using opioids for chronic non-cancer pain. Pain. 2007;128:355-362.

148. Zanger UM, Raimundo S, Eichelbaum M. Cytochrome P450 2D6: overview and update on pharmacology, genetics, biochemistry. Naunyn Schmiedebergs Arch Pharmacol. 2004;369:23-37.

149. Zhou SF. Polymorphism of human cytochrome P450 2D6 and its clinical significance: part 1. Clin Pharmacokinet. 2009;48: 689-723.

150. Kirchheiner J, Schmidt H, Tzvetkov M, et al. Pharmacokinetics of codeine and its metabolite morphine in ultra-rapid metabolizers due to CYP2D6 duplication. Pharmacogenomics J. 2007;7: 257-265.

151. Quang-Cantagrel ND, Wallace MS, Magnuson SK. Opioid substitution to improve the effectiveness of chronic noncancer pain control: a chart review. Anesth Analg. 2000;90:933-937.

152. Katz N, Fanciullo GJ. Role of urine toxicology testing in the management of chronic opioid therapy. Clin J Pain. 2002;18:S76-S82.

153. Manchikanti L, Atluri S, Trescot AM, Giordano J. Monitoring opioid adherence in chronic pain patients: tools, techniques, and utility. Pain Physician. 2008;11:S155-S180.

154. Woolf CJ, Hashmi M. Use and abuse of opioid analgesics: potential methods to prevent and deter non-medical consumption of prescription opioids. Curr Opin Investig Drugs. 2004;5:61-66.

155. US Food and Drug Administration. Joint meeting of the Anesthetic and Life Support Drugs Advisory Committee and the Drug Safety and Risk Management Advisory Committee: Risk Evaluation and Mitigation Strategies (REMS) for extended-release and longacting opioid analgesics. 2010. Available from: http://www.fda.gov/ downloads/Drugs/DrugSafety/InformationbyDrugClass/ucm217510. pdf. Accessed September 6, 2012.
156. Substance Abuse and Mental Health Services Administration. Results from the 2010 National Survey on Drug Use and Health: Summary of National Findings. Rockville (MD): Office of Applied Studies; 2011. Available from: http://www.samhsa.gov/data/ nsduh/2k10nsduh/2k10results.htm. Accessed July 30, 2012.

157. Manchikanti L, Singh A. Therapeutic opioids: a ten-year perspective on the complexities and complications of the escalating use, abuse, and nonmedical use of opioids. Pain Physician. 2008;11:S63-S88.

158. McCabe SE, Cranford JA, Boyd CJ, Teter CJ. Motives, diversion and routes of administration associated with nonmedical use of prescription opioids. Addict Behav. 2007;32:562-575.

159. Couto JE, Romney MC, Leider HL, Sharma S, Goldfarb NI. High rates of inappropriate drug use in the chronic pain population. Popul Health Manag. 2009;12:185-190.

160. Chabal C, Erjavec MK, Jacobson L, Mariano A, Chaney E. Prescription opiate abuse in chronic pain patients: clinical criteria, incidence, and predictors. Clin J Pain. 1997;13:150-155.

161. Manchikanti L, Pampati V, Damron KS, Fellows B, Barnhill RC, Beyer C. Prevalence of opioid abuse in interventional pain medicine practice settings: a randomized clinical evaluation. Pain Physician. 2001;4:358-365.

162. Katz NP, Sherburne S, Beach M, et al. Behavioral monitoring and urine toxicology testing in patients receiving long-term opioid therapy. Anesth Analg. 2003;97:1097-1102.

163. Fleming MF, Balousek SL, Klessig CL, Mundt MP, Brown DD. Substance use disorders in a primary care sample receiving daily opioid therapy. J Pain. 2007;8:573-582.

164. Webster LR, Bath B, Medve RA. Opioid formulations in development designed to curtail abuse: who is the target? Expert Opin Investig Drugs. 2009;18:255-263.

165. Katz N, Dart RC, Bailey E, Trudeau J, Osgood E, Paillard F. Tampering with prescription opioids: nature and extent of the problem, health consequences, and solutions. Am J Drug Alcohol Abuse. 2011;37:205-219.

166. Carise D, Dugosh KL, McLellan AT, Camilleri A, Woody GE, Lynch KG. Prescription OxyContin abuse among patients entering addiction treatment. Am J Psychiatry. 2007;164:1750-1756.

167. Young AM, Havens JR, Leukefeld CG. Route of administration for illicit prescription opioids: a comparison of rural and urban drug users. Harm Reduct J. 2010;7:24.

168. McClellan AT, Turner BJ. Chronic noncancer pain management and opioid overdose: time to change prescribing practices. Ann Intern Med. 2010;152:123-125.

169. Carroll CP, Haythornthwaite J. Maladaptive opioid use behaviors and psychiatric illness: what should we do with what we know? Curr Pain Headache Rep. 2011;15:91-93.

170. Jackman RP, Purvis JM, Mallett BS. Chronic nonmalignant pain in primary care. Am Fam Physician. 2008;78:1155-1162, 1164.

171. Wu LT, Woody GE, Yang C, Mannelli P, Blazer DG. Differences in onset and abuse/dependence episodes between prescription opioids and heroin: results from the national Epidemiologic Survey on Alcohol and Related Conditions. Subst Abuse Rehabil. 2011;2011:77-88.

172. NBC News. How Florida brothers' 'pill mill' operation fueled painkiller abuse epidemic [comments]. 2012. Available from: http://openchannel.msnbc.msn.com/_news/2012/05/07/11542417how-florida-brothers-pill-mill-operation-fueled-painkiller-abuseepidemic\#comments. Accessed December 29, 2012.

173. Farre M, Cami J. Pharmacokinetic considerations in abuse liability evaluation. Br J Addict. 1991;86:1601-1606.

174. Comer SD, Ashworth JB, Sullivan MA, Vosburg SK, Saccone PA, Foltin RW. Relationship between rate of infusion and reinforcing strength of oxycodone in humans. J Opioid Manag. 2009;5:203-212.

175. Butler SF, Fernandez KC, Chang A, et al. Measuring attractiveness for abuse of prescription opioids. Pain Med. 2010;11:67-80.

176. Webster LR, Bath B, Medve RA, Marmon T, Stoddard GJ. Randomized, double-blind, placebo-controlled study of the abuse potential of different formulations of oral oxycodone. Pain Med. 2012;13: 790-801. 
177. Katz N. Abuse-deterrent opioid formulations: are they a pipe dream? Curr Rheumatol Rep. 2008;10:11-18.

178. Budman SH, Serrano JMG, Butler SF. Can abuse deterrent formulations make a difference? Expectation and speculation. Harm Reduct J. 2009,6:8-15.

179. Johnson F, Setnik B. Morphine sulfate and naltrexone hydrochloride extended-release capsules: naltrexone release, pharmacodynamics, and tolerability. Pain Physician. 2011;14:391-406.

180. RegenceRx. Therapeutic class review: pain-long-acting opioids. 2010. Available from: http://www.regencerx.com/docs/physicianRx/painlong-acting-0410.pdf. Accessed December 29, 2012.

181. US Food and Drug Administration. FDA approves new formulation for OxyContin. 2010. Available from: http://www.fda.gov/NewsEvents/ Newsroom/PressAnnouncements/2010/ucm207480.htm. Accessed September 6, 2012.
182. Ling W, Mooney L, Hillhouse M. Prescription opioid abuse, pain and addiction: clinical issues and implications. Drug Alcohol Rev. 2011;30:300-305.

183. Office of National Drug Control Policy. Prescription drug abuse prevention plan. 2011. Available from: http://www.whitehouse.gov/sites/ default/files/ondcp/issues-content/prescription-drugs/rx_abuse_plan. pdf. Accessed January 28, 2013.

184. US Food and Drug Administration. Medication disposal: questions and answers. 2009. Available from: http://www.fda.gov/ Drugs/ResourcesForYou/Consumers/BuyingUsingMedicineSafely/ EnsuringSafeUseofMedicine/SafeDisposalofMedicines/ucm 186188. htm. Accessed November 17, 2012.

\section{Publish your work in this journal}

The Journal of Multidisciplinary Healthcare is an international, peerreviewed open-access journal that aims to represent and publish research in healthcare areas delivered by practitioners of different disciplines. This includes studies and reviews conducted by multidisciplinary teams as well as research which evaluates the results or conduct of such teams or healthcare processes in general. The journal covers a wide range of areas and welcomes submission from practitioners at all levels, from all over the world. The manuscript management system is completely online and includes a very quick and fair peer-review system. Visit http://www.dovepress.com/testimonials.php to read real quotes from published authors.

Submit your manuscript here: http://www.dovepress.com/journal-of-multidisciplinary-healthcare-journal 